\title{
Politique
}

Politique

\section{La mort apprivoisée de Moncef MARZOUKI, Montréal, Éditions du Méridien, 1990, 173 p.}

\section{Sylvain Labbé}

Numéro 19, hiver 1991

URI : https://id.erudit.org/iderudit/040693ar

DOI : https://doi.org/10.7202/040693ar

Aller au sommaire du numéro

Éditeur(s)

Société québécoise de science politique

ISSN

0711-608X (imprimé)

1918-6584 (numérique)

Découvrir la revue

Citer ce compte rendu

Labbé, S. (1991). Compte rendu de [La mort apprivoisée de Moncef MARZOUKI, Montréal, Éditions du Méridien, 1990, 173 p.] Politique, (19), 146-148.

https://doi.org/10.7202/040693ar

Ce document est protégé par la loi sur le droit d'auteur. L'utilisation des services d’Érudit (y compris la reproduction) est assujettie à sa politique d'utilisation que vous pouvez consulter en ligne.

https://apropos.erudit.org/fr/usagers/politique-dutilisation/
Cet article est diffusé et préservé par Érudit.

Érudit est un consortium interuniversitaire sans but lucratif composé de l'Université de Montréal, l'Université Laval et l'Université du Québec à Montréal. Il a pour mission la promotion et la valorisation de la recherche. https://www.erudit.org/fr/ 


\section{La mort apprivoisée}

de Moncef MARZOUKI, Montréal, Éditions du Méridien, 1990, $173 \mathrm{p}$.

Première question : pourquoi avons-nous peur de la mort? Deuxième question : un mythe explicatif de la mort permettrait-il de surmonter cette peur? En répondant à la première question et en proposant un mythe moderne qui nous permettrait d'apprivoiser notre peur de la mort, Moncef Marzouki nourrit l'espoir que ce mythe, parce que universel, rapprocherait les cultures.

Tunisien, médecin et professeur, Moncef Marzouki nous propose quatre regards sur l'expérience de la mort. Le premier de ces regards, $c^{\prime}$ est celui du médecin qui voit la mort 
survenir quotidiennement : une mort refusée vécue de manière traumatisante et dramatique qui se manifeste dans des conditions horribles. On l'aura compris, c'est notre mal de mourir que constate l'auteur. Nous adoptons une attitude de combat face à la mort, parce que nous la considérons comme un échec : échec de la science médicale certes, mais surtout échec de notre détermination à tout dominer, même la mort. Notre mal de mourir serait à mettre au compte de notre vision hédoniste et matérialiste du monde. Moncef Marzouki porte son regard sur notre réaction face à la mort (fuite, panique, refus) et découvre que cette réaction entraîne une angoisse face à son éventualité et une longue agonie lorsqu'elle survient : nous mourons mal parce qu' on a mal à mourir.

Les deux regards suivants, Moncef Marzouki les porte respectivement sur nos perceptions subjectives de la mort et sur les significations culturelles de celle-ci. II cherche d'une part à saisir l'expérience subjective de l'humain devant l'éventualité de sa mort. Il appréhende cette subjectivité en s'appuyant sur la poésie et la littérature, celles-ci constituant son lieu d'expression privilégié. Or, souligne-t-il, "les poètes de toutes cultures et de toutes époques disent à peu près la même chose : la mort est une catastrophe» (p. 82). Néanmoins, cette évidence n'entraîne pas forcément une attitude négative à l'égard de la mort : deux réactions sont possibles. Une première, constituée de crainte et d'espérance, ne peut mener qu'au refus de la mort. Ce n'est qu'en s'affranchissant de ces deux fardeaux que l'éventualité et la réalité de la mort pourraient être mieux "vécues». Précisément, c'est l'acceptation de l'idée de la mort et la certitude de son avènement qui constitueraient la deuxième réaction possible devant la mort.

Moncef Marzouki s'attarde ensuite au sens donné à la mort par différentes cultures. Encore ici, la constatation est la même : en faisant naître des sentiments de crainte, d'espérance, de culpabilité ou de vide, les significations données à la mort ne peuvent que provoquer drame, appréhension et déchirure face au grand départ. En refusant l'idée de la mort, les mythes explicatifs de la mort qui ont peuplé et peuplent l'imaginaire des collectivités humaines - que ce soit 
le modèle animiste, monothéiste ou athée - n'ont pu permettre à l'être humain de mourir sereinement.

En guise de dernier regard, Moncef Marzouki nous présente le brouillon de ce qui constituerait un «mythe collectif propre aux hommes de ce siècle". Ce mythe emprunte des éléments tant à la vision orientale du cosmos qu'à la science moderne. Au début, le big-bang, l'univers est simple et inorganisé; les années passent, l'univers se complexifie et s'organise. Un jour, apparaît l'être humain, produit de ce passage du simple au complexe; sa mort ne marque qu'une étape d'un processus plus vaste. Quoi de neuf par rapport au modèle athée de signification? La nouveauté se situerait dans l'adjonction d'une hypothèse de Jean Charon à l'effet que du chaos ne peut naître l'organisé que si l'on suppose un psychisme de la matière. L'électron, matière éternelle, accumulerait au fil du temps des informations qui permettraient la complexification de l'univers : I'électron est un super cerveau qui réfléchit, agit, connaît et aime. En conséquence, la vie et la mort sont des moments du processus de complexification cosmique. Nous ne mourons pas : nos expériences constituent des éléments de la mémoire de l'univers.

Ce mythe, nous dit Moncef Marzouki, n'est qu'une construction. Son avantage serait de "coller à l'activité de l'esprit en quête de sens" et permettrait ainsi à l'être humain de se libérer "de l'angoisse de vivre et de mourir". Mais voilà, pour séduisante que soit la fable, elle laisse notre imaginaire en appétit. Probablement que tout est fiction, même la science, mais encore faudrait-il distinguer rationalité et spiritualité. Moncef Marzouki n'y arrive pas : le spirituel ne venant que "confirmer" les hypothèses scientifiques. Le mythe proposé peut certes rendre serein quelques scientifiques, mais pour les autres... 